\title{
Detection of renal dysfunction based on serum creatinine levels in a Brazilian community. The Bambuí Health and Ageing Study
}

V.M.A. Passos ${ }^{1,3}$, S.M. Barreto ${ }^{2,3}$ M.F.F. Lima-Costa ${ }^{2,3}$ and the Bambuí Health and Ageing Study (BHAS) Group ${ }^{3 *}$

\author{
Departamentos de ${ }^{1}$ Clínica Médica and ${ }^{2}$ Medicina Preventiva e Social, \\ Faculdade de Medicina, Universidade Federal de Minas Gerais, \\ ${ }^{3}$ Laboratório de Epidemiologia e Antropologia Médica, \\ Centro de Pesquisas René Rachou, Fundação Oswaldo Cruz, \\ Belo Horizonte, MG, Brasil
}

Correspondence

V.M.A. Passos

Departamento de Clínica Médica

Faculdade de Medicina

UFMG

Av. Alfredo Balena, 190

30130-100 Belo Horizonte, MG

Brasil

Fax: +55-31-3248-9745

E-mail: vpassos@medicina.ufmg.br

*Contributors from the BHAS are listed in the Acknowledgments section. Research supported by FINEP. V.M.A. Passos, S.M. Barreto and M.F.F. Lima-Costa are fellows of CNPq.

Received May 8, 2002 Accepted October 14, 2002 ....................

\begin{abstract}
There are few population-based studies of renal dysfunction and none conducted in developing countries. In the present study the prevalence and predictors of elevated serum creatinine levels ( $\mathrm{SCr} \geq 1.3 \mathrm{mg} / \mathrm{dl}$ for men and $1.1 \mathrm{mg} / \mathrm{dl}$ for women) were determined among Brazilian adults (18-59 years) and older adults ( $>60$ years). Participants included all older adults $(\mathrm{N}=1742)$ and a probabilistic sample of adults $(\mathrm{N}=818)$ from Bambuí town, MG, Southeast Brazil. Predictors were investigated using multiple logistic regression. Mean SCr levels were $0.77 \pm 0.15 \mathrm{mg} / \mathrm{dl}$ for adults, $1.02 \pm 0.39 \mathrm{mg} / \mathrm{dl}$ for older men, and 0.81 $\pm 0.17 \mathrm{mg} / \mathrm{dl}$ for older women. Because there were only 4 cases $(0.48 \%)$ with elevated SCr levels among adults, the analysis of elevated SCr levels was restricted to older adults. The overall prevalence of elevated SCr levels among the elderly was 5.09\% (76/1494). The prevalence of hypercreatinemia increased significantly with age $\left(\chi^{2}=\right.$ $26.17, \mathrm{P}=0.000)$, being higher for older men $(8.19 \%)$ than for older women $\left(5.29 \%, \chi^{2}=5.00, \mathrm{P}=0.02\right)$. Elevated $\mathrm{SCr}$ levels were associated with age 70-79 years (odds ratio [OR] $=2.25,95 \%$ confidence interval $[\mathrm{CI}]$ : 1.15-4.42), hypertension $(\mathrm{OR}=3.04,95 \% \mathrm{CI}$ : 1.34-6.92), use of antihypertensive drugs $(\mathrm{OR}=2.46,95 \% \mathrm{CI}$ : $1.26-$ $4.82)$, chest pain ( $\mathrm{OR}=3.37,95 \% \mathrm{CI}: 1.31-8.74)$, and claudication $(\mathrm{OR}=3.43,95 \% \mathrm{CI}: 1.30-9.09)$ among men, and with age $>80$ years $(\mathrm{OR}=4.88,95 \% \mathrm{CI}: 2.24-10.65)$, use of antihypertensive drugs (OR $=4.06,95 \% \mathrm{CI}: 1.67-9.86)$, physical inactivity $(\mathrm{OR}=2.11,95 \% \mathrm{CI}$ : $1.11-4.02)$ and myocardial infarction $(\mathrm{OR}=3.89,95 \% \mathrm{CI}: 1.58-9.62)$ among women. The prevalence of renal dysfunction observed was much lower than that reported in other population-based studies, but predictors were similar. New investigations are needed to confirm the variability in prevalence and associated factors of renal dysfunction among populations.
\end{abstract}

Key words

- Serum creatinine

- Renal dysfunction

- Prevalence

- Community-based study 


\section{Introduction}

Very few population-based studies have investigated the prevalence and predictors of renal dysfunction worldwide, all of them performed in developed countries (1-4). Serum creatinine $(\mathrm{SCr})$ levels are the most commonly used marker for kidney function in clinical practice and elevated SCr levels are a predictor of end-stage renal disease (ESRD). Aging has been associated with physiological and pathological changes in renal function and several pathological conditions are implicated in these alterations, the most important being hypertension, diabetes and atherosclerosis (3). In a community-based study in the United States, the prevalence of elevated $\mathrm{SCr}$ levels increased from $2.5 \%$ in the 20 - to 49 -year age group to approximately $8.0 \%$ for subjects 60 years of age (1). In Brazil, the mortality rate for chronic renal failure increases exponentially with age, being 12.75 per million population (PMP) in the 25- to 34-year age group, 324.7 PMP in the 65- to 74-year age group and 893.99 PMP among those of $>75$ years (5).

We present here the results of a population-based study in Brazil which was carried out to detect the prevalence and predictors of elevated SCr among adults and a cohort of older adults. To our knowledge, this is the first community-based study of renal function among individuals living in a developing country.

\section{Material and Methods}

\section{Study design and population}

We analyzed the baseline data of the Bambuí Health and Ageing Study (BHAS), an on-going prospective study of older adults (6). Bambuí is located in the State of Minas Gerais in Southeast Brazil and had about 20,000 inhabitants in 1996. It was formerly an important endemic area for Chagas' disease and, even though the transmission of
Trypanosoma cruzi has been interrupted for nearly 20 years, the prevalence of infection remains high in the elderly population due to a cohort effect (7).

All residents aged $>60$ years $(\mathrm{N}=1742)$ and a non-replaceable simple probabilistic sample of adults aged 18-59 years were selected for interview and examination. The sample size of adults $(1,020 / 8,899)$ was sufficient to estimate a prevalence of risk factors $=0.50$, with a confidence interval $=$ 0.95 , losses $=0.20$ and precision $=0.03$. Older and younger participants were similar to the town population regarding sex, age, marital status, monthly family income and education (6).

This study was conducted according to the guidelines of the Helsinki Declaration and approved by the Ethics Committee of FIOCRUZ. Participation was voluntary and the participants signed an informed consent form. Interviews, physical measurements and blood tests were carried out between January and August 1997 (6).

Blood pressure was measured 30 or more minutes after the last caffeine intake or cigarette smoked. Three measurements were made, one after 5 min of initial rest and the other two at 2-min intervals. The final blood pressure value was taken to be the arithmetic mean of the second and third measurements (8). Hypertension was defined as diastolic blood pressure (DBP) $\geq 90 \mathrm{mmHg}$ and/or systolic blood pressure (SBP) $\geq 140 \mathrm{mmHg}$ and/or current use of antihypertensive medication. Isolated systolic hypertension was defined as DBP $<90 \mathrm{mmHg}$ and SBP $\geq 140$ mmHg (8). Participants were questioned about the use of cimetidine, antihypertensive drugs, insulin, hypoglycemic agents, antibiotics and nonsteroidal anti-inflammatory drugs during the last three months.

Diabetes was defined as a fasting blood glucose level of $126 \mathrm{mg} / \mathrm{dl}$ or more or the report of current use of insulin or hypoglycemic agents. The diagnosis of chest pain and intermittent claudication was defined based 
on a WHO standard questionnaire (9). Stroke and myocardial infarction were identified on the basis of patient medical history.

\section{Laboratory tests}

Glucose, total cholesterol, HDLc, LDLc and triglyceride levels were determined after a 12-h fast. An automated analyzer (Eclipse Vitalab, Merck do Brasil, São Paulo, SP, Brasil), calibrated according to manufacturer specifications was used to determine $\mathrm{SCr}$ by the Jaffe alkaline picrate reaction (6). Serology status for $T$. cruzi was determined using indirect hemagglutination (Biolab, Ackland, New Zealand) and enzyme linked immunoabsorbent assay (Abbott Brazil, São Paulo, SP, Brazil) (6). Creatinine clearance was estimated by the Cockcroft-Gault equation [140 - age (years) x weight $(\mathrm{kg}) / 72 \times \mathrm{SCr}$ $(\mathrm{mg} \%)]$. The result was multiplied by 0.85 for women (10).

\section{Statistical analysis}

Analyses were stratified by sex since differences in SCr levels and lean body mass have been well defined (11). Estimates were weighted to allow for the difference in sampling probability of adults and older adults in order to represent the total urban adult population. The one-sample $t$-test was used for comparisons between means and the designbased Pearson chi-square test for proportions (12). Multiple logistic regression analysis (13) was used to investigate the predictors of elevated SCr levels based on international normal range values (0.6-1.1 for women and 0.7-1.3 for men) (14). The criterion for the inclusion of a variable in the logistic model was association with elevated SCr levels in the univariate analysis at a level below 0.10 . The final model retained all variables associated with elevated $\mathrm{SCr}$ levels at a level below 0.05 . The analysis was carried out using Stata statistical software (15). Additional details of the methods have been published elsewhere (6).

\section{Results}

Table 1 summarizes the baseline characteristics of adults and older adults. When compared to adults, older adults presented a significantly lower prevalence of smokers $\left(\chi^{2}=42.92, \mathrm{P}=0.000\right)$ and a significantly higher frequency of higher total cholesterol levels $\left(\chi^{2}=622.25, \mathrm{P}=0.000\right)$, physical inactivity $\left(\chi^{2}=135.97, \mathrm{P}=0.000\right)$, hyperten$\operatorname{sion}\left(\chi^{2}=42.36, \mathrm{P}=0.000\right)$, isolated systolic hypertension $\left(\chi^{2}=106.03, \mathrm{P}=0.000\right)$, use of antihypertensive drugs $\left(\chi^{2}=269.27, \mathrm{P}=\right.$ $0.000)$, diabetes $\left(\chi^{2}=84.00, \mathrm{P}=0.000\right)$, previous myocardial infarction $\left(\chi^{2}=24.48\right.$, $\mathrm{P}=0.000)$ and stroke $\left(\chi^{2}=9.10, \mathrm{P}=0.003\right)$, and a history of intermittent claudication $\left(\chi^{2}=4.26, \mathrm{P}=0.039\right)$.

The sex-specific 95 th percentile cut-offs for $\mathrm{SCr}$ were $1.3 \mathrm{mg} / \mathrm{dl}$ for men and $1.2 \mathrm{mg} / \mathrm{dl}$ for women. Mean SCr level was $0.77 \mathrm{mg} / \mathrm{dl}$ $(\mathrm{SD}=0.15$, median 0.76$)$, ranging from 0.23 to $1.37 \mathrm{mg} / \mathrm{dl}$ among 818 adults (18-59 years). Because there were only four cases $(0.48 \%)$ with elevated SCr level among adults, the analysis of elevated $\mathrm{SCr}$ levels was limited to older adults ( $>60$ years).

Of a total of 1742 residents aged $>60$ years, $1494(85.76 \%)$ older adults participated in this study. Mean \pm SD SCr level was $1.02 \pm 0.39 \mathrm{mg} / \mathrm{dl}$ (median $0.97 \mathrm{mg} / \mathrm{dl}$ ) for men and $0.81 \pm 0.17 \mathrm{mg} / \mathrm{dl}$ (median 0.78 $\mathrm{mg} / \mathrm{dl}$ ) for women. The overall prevalence of elevated SCr levels among elderly was 5.09\% (76/1494). Figure 1 shows the mean $\mathrm{SCr}$ levels by age and sex among older adults. There was a significant difference in sexspecific prevalences $\left(\chi^{2}=5.00, \mathrm{P}=0.02\right)$, with the prevalence being $8.19 \%$ (47/586) among men and 5.29\% (29/908) among women. The prevalence of elevated SCr increased significantly with age $\left(\chi^{2}=26.17\right.$, $\mathrm{P}=0.000)$ from $4.2 \%(37 / 882)$ among subjects aged $60-69$ years to $8.00 \%$ (37/462) among subjects aged $70-79$ years and $14.67 \%$ 


\begin{tabular}{|c|c|c|c|c|}
\hline \multirow{3}{*}{$\begin{array}{l}\text { Characteristic } \\
\text { Age (mean, years) }\end{array}$} & \multicolumn{2}{|c|}{ Adults (18-59 years) } & \multicolumn{2}{|c|}{ Older adults (>60 years) } \\
\hline & Men & Women & Men & Women \\
\hline & $35.9 \pm 12.1$ & $36.6 \pm 11.4$ & $68.8 \pm 7.1$ & $69.3 \pm 7.2$ \\
\hline BMI (mean, kg/m²) & $24.4 \pm 3.6$ & $25.2 \pm 5.2$ & $23.9 \pm 4.1$ & $25.8 \pm 5.2$ \\
\hline $\mathrm{SCr}$ (mean, mg/dl) & $0.9 \pm 0.1$ & $0.7 \pm 0.1$ & $1.0 \pm 0.4$ & $0.8 \pm \quad 0.1$ \\
\hline Glucose (mean, mg/dl) & $96.2 \pm 22.6$ & $103.1 \pm 36.7$ & $107.9 \pm 45.4$ & $109.0 \pm 41.9$ \\
\hline Uric acid (mean, mg/dl) & $5.7 \pm 1.6$ & $4.1 \pm 1.4$ & $5.8 \pm 1.7$ & $5.02 \pm 1.6$ \\
\hline Cholesterol (mean, mg/dl) ${ }^{1}$ & $186.6 \pm 41.4$ & $186.1 \pm 41.8$ & $219.7 \pm 46.0$ & $241.8 \pm 49.1$ \\
\hline HDLc (mean, mg/dl) & $49.4 \pm 15.3$ & $53.0 \pm 14.7$ & $46.9 \pm 15.7$ & $50.6 \pm 14.4$ \\
\hline Triglycerides (mean, mg/dl) & $142.6 \pm 115.2$ & $123.5 \pm 84.0$ & $135.7 \pm 89.9$ & $168.9 \pm 107.3$ \\
\hline Current smoker $(\%)^{2}$ & 38.8 & 24.0 & 30.6 & 9.9 \\
\hline Physical inactivity $(\%)^{3}$ & 10.3 & 13.7 & 28.3 & 38.7 \\
\hline SBP (mean, mmHg) & $118.3 \pm 17.3$ & $112.6 \pm 18.9$ & $137.7 \pm 23.0$ & $137.1 \pm 22.4$ \\
\hline $\mathrm{DBP}$ (mean, mmHg) & $77.4 \pm 11.4$ & $74.4 \pm 12.8$ & $85.0 \pm 13.3$ & $82.4 \pm 12.2$ \\
\hline Hypertension $(\%)^{4}$ & 18.0 & 22.1 & 59.7 & 59.8 \\
\hline Isolated systolic hypertension $(\%)^{5}$ & 1.9 & 2.4 & 14.0 & 18.0 \\
\hline Nonsteroidal anti-inflammatory drug (\%) & 7.2 & 12.6 & 8.4 & 14.9 \\
\hline Antihypertensive drug $(\%)^{6}$ & 3.9 & 9.2 & 23.6 & 48.4 \\
\hline Diabetes $(\%)^{7}$ & 0.2 & 2.6 & 12.8 & 15.7 \\
\hline Chest pain (\%) & 4.7 & 10.0 & 6.0 & 10.7 \\
\hline Myocardial infarction $(\%)^{8}$ & 0.8 & 1.1 & 5.7 & 4.6 \\
\hline Claudication $(\%)^{9}$ & 1.1 & 1.3 & 1.0 & 4.8 \\
\hline Stroke $(\%)^{10}$ & 1.1 & 2.2 & 3.7 & 4.2 \\
\hline
\end{tabular}

Data are reported as mean \pm SD when applicable. Statistically significant differences between adults and older adults: ${ }^{1} \chi^{2}=622.25, P=0.000 ;{ }^{2} \chi^{2}=42.92, P=0.000 ;{ }^{3} \chi^{2}=135.97, P=0.000 ;{ }^{4} \chi^{2}=42.36, P=0.000$; ${ }^{5} \chi^{2}=106.03, P=0.000 ;{ }^{6} \chi^{2}=269.27, P=0.000 ;{ }^{7} \chi^{2}=84.00, P=0.000 ;{ }^{8} \chi^{2}=24.48, P=0.000 ;{ }^{9} \chi^{2}=4.26$, $\mathrm{P}=0.039 ;{ }^{10} \chi^{2}=9.10, \mathrm{P}=0.003$. $\mathrm{BMI}=$ body mass index; $\mathrm{SCr}=$ serum creatinine; $\mathrm{SBP}, \mathrm{DBP}=$ systolic and diastolic blood pressure, respectively.

Figure 1. Prevalence of elevated serum creatinine levels by age and sex among the Bambui Health and Ageing Study participants.

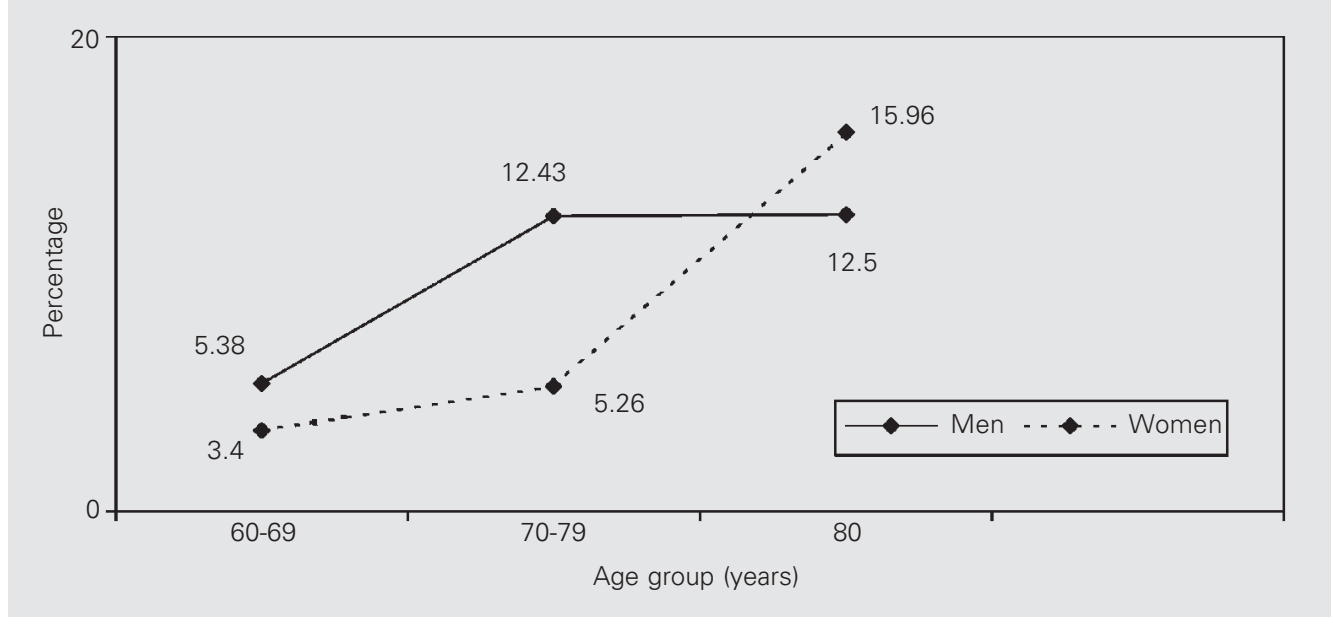


$(22 / 150)$ among subjects aged $>80$ years. Mean SCr increased with age for both sexes, with a more pronounced increase in women than in men (Table 2). There was also a significant decrease in estimated creatinine clearance with age $(74.82 \pm 23.86 \mathrm{ml} / \mathrm{min}$ for subjects aged 60-69 years, $59.02 \pm 20.94$ $\mathrm{ml} / \mathrm{min}$ for subjects aged 70-79 years, and $44.15 \pm 13.04 \mathrm{ml} / \mathrm{min}$ for subjects aged $>80$ years). There was no significant difference in mean body mass index (BMI) between adults and older adults (Table 1) and no significant association between BMI and elevated SCr levels $\left(\chi^{2}=0.83, \mathrm{P}=0.66\right)$.

Hypertension was diagnosed in $61.51 \%$ (919/1474) of the older adults. Of 919 hypertensive older adults, 635 (69.1\%) were taking one or more of the following drugs: $346(54.5 \%)$ thiazides, $178(28.0 \%) \mathrm{K}^{+}$-sparing diuretics (spironolactone or amiloride), $210(33.1 \%)$ angiotensin-converting enzyme (ACE) inhibitors, $143(22.5 \%)$ calcium channel blockers, 120 (18.9\%) were using sympathicolytic agents (methyldopa or prazo$\sin ), 58(9.1 \%)$ beta-adrenergic antagonists, and $57(8.9 \%)$ furosemide. The use of thiaz- ide, furosemide and ACE inhibitors was significantly associated with elevated SCr levels. However, after adjustment for hypertension, the association between elevated $\mathrm{SCr}$ levels and the use of thiazides and furosemide disappeared. On the other hand, the positive association between elevated $\mathrm{SCr}$ levels and use of ACE inhibitors remained significant, even after adjustment for hypertension (odds ratio $[\mathrm{OR}]=1.89,95 \%$ confidence interval [CI]: 1.21-3.19). None of the other drugs investigated (antibiotics and the diuretics and nonsteroidal anti-inflammatory drugs used in combination) were associated with elevated SCr levels. Twenty-one elderly subjects were taking sulfamethoxazoletrimethoprim and its use was not associated with elevated SCr levels $\left(\chi^{2}=0.0047, \mathrm{P}=\right.$ 0.946). There was no association between positive $T$. cruzi serology and hypercreatinemia.

Despite the low use of cimetidine (6/ 1494 or $0.40 \%$ ), the use of the drug was associated with elevated $\mathrm{SCr}$ levels $\left(\chi^{2}=\right.$ 9.96, $\mathrm{P}=0.002$ ) among older adults. Because there was no difference in the results

Table 2. Serum creatinine (SCr) and estimated creatinine clearance values by age and sex (Bambuí Health and Ageing Study).

\begin{tabular}{lccc}
\hline & \multicolumn{3}{c}{ Age group (years) } \\
\cline { 2 - 4 } & $60-69$ & $70-79$ & $>80$ \\
\hline Men (N) & 353 & 177 & 56 \\
SCr (mg/dl): mean $\pm \mathrm{SD}$ & $0.98 \pm 0.32$ & $1.05 \pm 0.26$ & $1.17 \pm 0.82$ \\
(range) & $(0.22-5.95)$ & $(0.63-2.53)$ & $(0.78-6.96)$ \\
Prevalence of elevated SCr levels & $5.38(\mathrm{~N}=19)$ & $12.43(\mathrm{~N}=22)$ & $10.71(\mathrm{~N}=6)$ \\
Creatinine clearance (ml/min)* & $77.19 \pm 25.42$ & $58.56 \pm 17.00$ & $46.56 \pm 14.32$ \\
(median) & $(74.32)$ & $(57.70)$ & $(45.32)$ \\
Women (N) & 529 & 285 & 94 \\
SCr (mg/dl): mean $\pm \mathrm{SD}$ & $0.79 \pm 0.15$ & $0.82 \pm 0.17$ & $0.89 \pm 0.24$ \\
(range) & $(0.32-1.91)$ & $(0.16-1.95)$ & $(0.40-1.75)$ \\
Prevalence of elevated SCr levels & $2.08(\mathrm{~N}=11)$ & $2.81(\mathrm{~N}=8)$ & $10.64(\mathrm{~N}=10)$ \\
Creatinine clearance (ml/min)* & $73.23 \pm 22.65$ & $59.31 \pm 23.04$ & $42.50 \pm 11.91$ \\
(median) & $(70.11)$ & $(56.71)$ & $(40.82)$ \\
\hline
\end{tabular}

${ }^{*}$ Creatinine clearance was estimated using the Cockcroft-Gault equation. 
after exclusion of elderly subjects taking cimetidine, these individuals were kept in the final analysis.

Diabetes was diagnosed in $14.52 \%$ (217/ 1494) of older adults and in $22.36 \%$ (17/76) of those with elevated $\mathrm{SCr}$ levels. A positive association was detected between hypercreatinemia and diabetes $(\mathrm{OR}=1.81,95 \% \mathrm{CI}$ : 1.03-3.18), but this association disappeared with further adjustment for hypertension $(\mathrm{OR}=1.61,95 \%$ CI: 0.91-2.82).

In the multivariate analysis, elevated $\mathrm{SCr}$ levels in older men continued to be significantly associated with age 70-79 years (OR $=2.25,95 \%$ CI: 1.15-4.42), hypertension $(\mathrm{OR}=3.04,95 \% \mathrm{CI}=1.34-6.92)$, use of antihypertensive drugs $(\mathrm{OR}=2.46,95 \% \mathrm{CI}$ : 1.26-4.82), chest pain $(\mathrm{OR}=3.37,95 \% \mathrm{CI}$ : 1.31-8.74) and intermittent claudication (OR $=3.43$, 95\% CI: $1.30-9.09$ ) (Table 3). Among older women, elevated $\mathrm{SCr}$ levels were associated with age $>80$ years $(\mathrm{OR}=4.88,95 \%$ CI: 2.24-10.65), use of antihypertensive drugs $(\mathrm{OR}=4.06,95 \% \mathrm{CI}: 1.67-9.86)$, physical inactivity $(\mathrm{OR}=2.11,95 \% \mathrm{CI}: 1.11-4.02)$, and a report of previous myocardial infarction $(\mathrm{OR}=3.89,95 \%$ CI: 1.58-9.62) (Table 4).

\section{Discussion}

We found a low prevalence of elevated SCr among older adults in the study community and a negligible prevalence of elevated SCr levels among the adult population. Compared to the prevalence reported for the aged population ( $>60$ years) of the Framingham Study, our results are two- to three-fold lower, despite the higher cut-offs used by the latter to define renal dysfunction $(1.5 \mathrm{mg} / \mathrm{dl}$ for men and $1.4 \mathrm{mg} / \mathrm{dl}$ for women) (1). The prevalence in our study was also half of that found by the ARIC Study in a much younger population (45-64 years) (4). Moreover, the mean creatinine levels of older men and women were consistently lower than those found in another US study (3).

Because the prevalence of elevated $\mathrm{SCr}$ levels predicts ESRD and correlates with morbidity and mortality from renal disease, we investigated the national rates of ESRD.

Table 3. Predictors of elevated serum creatinine $(\mathrm{SCr})$ levels for men $(\geq 1.3 \mathrm{mg} / \mathrm{dl})$ in the multivariate analysis (Bambuí Health and Ageing Study).

\begin{tabular}{|c|c|c|c|c|}
\hline Variable & $\begin{array}{l}\text { Elevated } \mathrm{SCr} \\
\text { levels }\end{array}$ & $\begin{array}{l}\text { Normal SCr } \\
\text { levels }\end{array}$ & $\begin{array}{l}\text { Crude odds ratio } \\
\qquad(95 \% \mathrm{Cl})\end{array}$ & $\begin{array}{l}\text { Adjusted odds } \\
\text { ratio }(95 \% \mathrm{Cl})^{*}\end{array}$ \\
\hline \multicolumn{5}{|c|}{ Age group (years) } \\
\hline 60-69 & 19 & 334 & 1.00 & 1.00 \\
\hline $70-79$ & 22 & 155 & $2.50(1.31-4.74)$ & $2.25(1.15-4.42)$ \\
\hline$>80$ & 7 & 49 & $2.51(1.00-6.28)$ & $3.12(1.19-8.26)$ \\
\hline \multicolumn{5}{|c|}{ Hypertension } \\
\hline No & 10 & 560 & 1.00 & 1.00 \\
\hline Yes & 40 & 337 & $3.96(1.88-8.34)$ & 3.04 (1.34-6.92) \\
\hline \multicolumn{5}{|c|}{ Antihypertensive medication } \\
\hline No & 19 & 377 & 1.00 & 1.00 \\
\hline Yes & 31 & 161 & $3.90(2.12-7.20)$ & $2.46(1.26-4.82)$ \\
\hline \multicolumn{5}{|c|}{ Chest pain } \\
\hline No & 41 & 507 & 1.00 & 1.00 \\
\hline Yes & 7 & 28 & $3.09(1.27-7.51)$ & $3.37(1.31-8.74)$ \\
\hline \multicolumn{5}{|c|}{ Claudication } \\
\hline No & 41 & 511 & 1.00 & 1.00 \\
\hline Yes & 7 & 21 & $4.15(1.66-10.34)$ & 3.43 (1.30-9.09) \\
\hline
\end{tabular}

*Adjusted according to all variables included in the table and according to proxy respondent. 
The three major causes of ESRD in Brazil are chronic glomerulonephritis, hypertensive nephrosclerosis and diabetic nephropathy (16). The Brazilian prevalence rates of ESRD were 312 PMP in 1997 (5) and are similar to rates found in other developing countries, but two- to three-fold lower than those reported for developed countries. For instance, the prevalence rates of treated ESRD vary from less than 350 PMP in countries such as Chile, Czechoslovakia and Poland to 600-700 in Spain, France and Italy, 975 in the US, and 1,230 in Japan (17). The low rates of ESRD reported in Brazil are consistent with our findings of a low prevalence of elevated SCr.

As expected, a strong association of elevated SCr levels with age, regardless of sex, was observed. Because population aging is a recent phenomenon in Brazil and due to a low life expectancy, our aged population is younger than the aged population of developed countries. A somewhat smaller fraction of people aged $>70$ years might explain in part the low prevalence of elevated $\mathrm{SCr}$ found in the present study.

All predictors of elevated $\mathrm{SCr}$ are related to hemodynamic aspects of renal function.
In men and women, hypercreatinemia was associated with treatment of hypertension, regarded as a marker for more severe disease. This association suggests kidney damage by the disease and/or the use of antihypertensive drugs $(3,4)$. The higher frequency of ischemic diseases in men (chest pain and intermittent claudication) and women (history of myocardial infarction) with renal dysfunction supports the role of low renal perfusion pressure in its pathogenesis. In this community, the prevalence of hypertension is very high and $92 \%$ were also exposed to other cardiovascular risk factors (18). Effective management of hypertension remains the most important strategy in attempting to retard the progressive loss of renal function that occurs with age and can be hastened by elevated blood pressure levels $(19,20)$.

Although considered applicable to older people with stable kidney function (21), the creatinine clearance inferred by the Cockcroft-Gault equation is not a good indicator of renal function in this population $(3,22)$. In this community, we observed an important decline in creatinine clearance with age determined by this equation, that was not con-

\begin{tabular}{|c|c|c|c|c|}
\hline Variable & $\begin{array}{c}\text { Elevated } \mathrm{SCr} \\
\text { levels }\end{array}$ & $\begin{array}{l}\text { Normal } \mathrm{SCr} \\
\text { levels }\end{array}$ & $\begin{array}{l}\text { Crude odds ratio } \\
\qquad(95 \% \mathrm{Cl})\end{array}$ & $\begin{array}{l}\text { Adjusted odds } \\
\text { ratio }(95 \% \mathrm{Cl})^{*}\end{array}$ \\
\hline \multicolumn{5}{|c|}{ Age group (years) } \\
\hline $60-69$ & 18 & 511 & 1.00 & 1.00 \\
\hline $70-79$ & 15 & 270 & $1.57(0.78-3.18)$ & $1.47(0.71-3.08)$ \\
\hline$>80$ & 15 & 79 & $5.61(2.31-13.61)$ & $4.88(2.24-10.65)$ \\
\hline \multicolumn{5}{|c|}{ Antihypertensive medication } \\
\hline No & 4 & 361 & 1.00 & 1.00 \\
\hline Yes & 25 & 518 & $5.01(2.11-11.93)$ & $4.06(1.67-9.86)$ \\
\hline \multicolumn{5}{|c|}{ Physical inactivity } \\
\hline No & 17 & 540 & 1.00 & 1.00 \\
\hline Yes & 31 & 320 & $3.08(1.67-5.65)$ & $2.11(1.11-4.02)$ \\
\hline \multicolumn{5}{|c|}{ History of myocardial infarction } \\
\hline No & 24 & 837 & 1.00 & 1.00 \\
\hline Yes & 5 & 36 & $5.11(2.21-11.79)$ & $3.89(1.58-9.62)$ \\
\hline
\end{tabular}

${ }^{*}$ Adjusted according to all variables included in the table and according to proxy respondent. 
sistent with the age-group prevalence of hypercreatinemia.

Because people with elevated SCr levels have a higher probability to die prematurely, we cannot rule out survival bias in this study. Although survival bias also affects the community-based studies conducted in developed countries, we cannot exclude that the low prevalence of renal dysfunction found in this study reflects a possible lower survival of patients with renal dysfunction due to differences in access to and use of health care. Selective migration of ESRD patients is also an unlikely explanation for the low prevalence of elevated SCr in the study community because a dialysis service is available in a neighboring city, and the transportation of patients is free.

A reasonable question resulting from our findings is whether the international reference values are too high. These parameters have not been tested in the older population of developing countries which might present a different clinical and lifestyle background from developed countries.
Since there are very few population-based studies of renal function worldwide and because the present one is the first study of this kind in a developing country, it is important to determine whether the low prevalence of elevated SCr levels found in this community applies to other developing and developed countries, and to investigate the factors associated with variability in prevalence rates. Epidemiological studies should also be designed to test the adequacy of international reference values of $\mathrm{SCr}$ for older populations from developing countries. Such information is important for the diagnosis and prevention of ESRD.

\section{Acknowledgments}

The authors would like to thank the following members of the BHAS Group for their contributions to this study: J.O.A. Firmo, H.L. Guerra, P.G. Vidigal and E. Uchôa. We thank all the people in the BHAS who gave free and informed consent to participate in this study.

\section{References}

1. Culleton BF, Larson MG, Evans JC, Wilson PWF, Barrett BJ, Parfrey OS \& Levy D (1999). Prevalence and correlates of elevated serum creatinine levels. Archives of Internal Medicine, 159: 1785-1790.

2. Iseki K, Ikemiya Y \& Fufiyama K (1997). Risk factors of end-stage renal disease and serum creatinine in a community-based massscreening. Kidney International, 51: 850-854.

3. Salive ME, Jones CA, Guralnik JM, Agodoa LY, Pahor M \& Wallace RB (1995). Serum creatinine in older adults: relationship with health status and medications. Age and Ageing, 24: 142-150.

4. Perneger TV, Nieto J, Whelton PK, Klag MJ, Comstock GW \& Szklo M (1993). A prospective study of blood pressure and serum creatinine. Journal of the American Medical Association, 269: 488-493.

5. DATASUS, National Brazilian Health Data System (1998). Morbidity and Mortality Information 1979-96. Ministry of Health, Brasília, DF, Brazil.

6. Lima e Costa MFFL, Uchôa E, Guerra HL, Firmo JOA, Vidigal PG \& Barreto SM (2000). The Bambuí Health and Ageing Study (BHAS). Methodological approach and preliminary results of a populationbased cohort study of the elderly in Brazil. Revista de Saúde Pública, 34: 126-135

7. Lima-Costa MFFL, Barreto SM, Guerra HL, Firmo JOA, Uchoa E \& Vidigal PG (2001). Ageing with Trypanosoma cruzi infection in a community where the transmission has been interrupted: the
Bambuí Health and Ageing Study (BHAS). International Journal of Epidemiology, 30: 887-893.

8. Joint National Committee on Prevention, Detection, Evaluation, and Treatment of High Blood Pressure and National High Blood Pressure Education Program Coordinating Committee (1997). The Sixth Report of the Joint National Committee on Prevention, Detection, Evaluation, and Treatment of High Pressure. Archives of Internal Medicine, 157: 2413-2446.

9. Rose GA, McCartney P \& Reid DD (1977). Self-administration of a questionnaire on chest pain and intermittent claudication. British Journal of Preventive and Social Medicine, 31: 42-48.

10. Cockcroft DW \& Gault MH (1976). Prediction of creatinine clearance from serum creatinine. Nephron, 16: 31-41.

11. Shulmann NB, Ford CE \& Hall WD (1989). Hypertension Detection and Follow-up Program Cooperative Group: prognostic value of serum creatinine and effect of treatment of hypertension on renal function - Results from the hypertension detection and follow-up program. Hypertension, 13: 180-193.

12. Armitage P \& Berry G (1987). Statistical Methods in Medical Research. 2nd edn. Blackwell Scientific Publication, Oxford, UK.

13. Kahn HÁ \& Sempos CT (1989). Statistical Methods in Epidemiology. Oxford University Press, New York, NY, USA.

14. Tietz NW, Shuey DF \& Weksteins DR (1992). Laboratory values in fit 
aging individuals - sexagenarians through centenarians. Clinical Chemistry, 38: 1167-1185.

15. Stata Statistical Software (1997). Release 6.0. Stata Corporation, College Station, TX, USA.

16. Noronha IL, Schor N, Coelho SN, Jorgetti V, Romão Jr JE, Zatz R \& Burdmann EA (1997). Nephrology, dialysis and transplantation in Brazil. Nephrology, Dialysis, Transplantation, 12: 2234-2243.

17. National Institute of Diabetes and Digestive and Kidney Diseases (1997). US Renal Data System, 1997 Annual Data Report. National Institutes of Health, Bethesda, MD, USA.

18. Barreto SM, Passos VMA, Firmo JOA, Guerra HL, Vidigal PG \& LimaCosta MFF (2001). Hypertension and clustering of cardiovascular risk factors in a community in Southeast Brazil. The Bambuí Health and Ageing Study. Arquivos Brasileiros de Cardiologia, 77: 576-581.

19. Felicetta JV (2001). Renal considerations in the older hypertensive patients. Clinical Geriatrics. Available at: www.mmhc.com/cg/ articles/CG9803/Felicetta.html. Accessed January 22, 2002.

20. National High Blood Pressure Education Program (1991). National High Blood Pressure Education Program Working Group Report on hypertension and chronic renal failure. Archives of Internal Medicine, 151: 1280-1287.

21. Coyle JM, Bhowmick BK \& Meara RJ (1999). Measuring renal function in old age. Reviews in Clinical Gerontology, 9: 215-219.

22. Porush JG \& Faubert PF (1997). Renal disease in elderly patients. Reviews in Clinical Gerontology, 7: 299-307. 